\title{
ESTIMATIVA DOS COMPONENTES DO BALANÇO DE ENERGIA E DA EVAPOTRANSPIRAÇÃO EM PLANTIOS DE EUCALIPTO UTILIZANDO O ALGORITMO SEBAL E IMAGEM LANDSAT 5 - TM ${ }^{1}$
}

\author{
Sady Júnior Martins da Costa de Menezes², Gilberto Chohaku Sediyama³, Vicente Paulo Soares ${ }^{4}$, \\ José Marinaldo Gleriani ${ }^{4}$ e Ricardo Guimarães Andrade ${ }^{5}$
}

\begin{abstract}
RESUMO - Variáveis climáticas são essenciais para a compreensão das condições ambientais que influenciam o crescimento e o desenvolvimento vegetal. Nos últimos anos, as pesquisas que utilizam dados climáticos e técnicas de sensoriamento remoto em análises espaço-temporais da demanda por água e energia das plantas têm-se intensificado. O SEBAL (Surface Energy Balance Algorithms for Land) é um dos algoritmos mais destacados em estudos que envolvem estimativas dos fluxos de energia em grandes áreas, e pode ser aplicado com poucas medições de campo. Este trabalho, realizado no Município de Santa Bárbara, Minas Gerais, objetivou estimar os componentes do balanço de energia e, por conseguinte, a evapotranspiração em plantios de eucalipto com aplicação do algoritmo SEBAL e de imagem do sensor TM do satélite Landsat 5 . As estimativas foram realizadas para cena do dia 20/06/2003. Considerando apenas as áreas referentes aos plantios de eucalipto (sete anos de idade), foram obtidos valores médios de saldo de radiação (Rn), fluxo de calor no solo (G), fluxo de calor sensível (H), fluxo de calor latente (LE) de 420,12 $\mathrm{W} \mathrm{m}^{-2}, 81,80 \mathrm{~W} \mathrm{~m}^{-2}, 149,93 \mathrm{~W} \mathrm{~m}^{-2}, 188,39 \mathrm{~W} \mathrm{~m}^{-2}$, respectivamente. Para a evapotranspiração real horária $\left(\operatorname{ETr}_{\mathrm{h}}\right)$, o valor médio obtido foi de $0,28 \mathrm{~mm} \mathrm{~h}^{-1}$. As estimativas mostraram-se condizentes com dados da literatura, no entanto pesquisas com maior controle experimental devem ser realizadas.
\end{abstract}

Palavras-chave: Plantio de eucalipto, Fluxos de energia e Sensoriamento remoto.

\section{ESTIMATION OF ENERGY BALANCE COMPONENTS AND EVAPOTRANSPIRATION IN EUCALYPTUS CROPS USING THE SEBAL ALGORITHM AND LANDSAT 5 TM IMAGE}

\begin{abstract}
Climatic variables are essential for understanding the environmental conditions that influence plant growth and development. In the last years, research works which use climatic data and remote sensing techniques in spatial and temporal analyses of the demand for water and energy in plants has been intensified. SEBAL (Surface Energy Balance Algorithms for Land) is one of the most prominent algorithms for studies involving energy flow estimates in large areas, and it can be applied with few field measurements. The objective of this work, conducted in the municipality of Santa Bárbara, Minas Gerais, Brazil, was to estimate energy balance components, and therefore the evapotranspiration in eucalyptus crops by applying the SEBAL algorithm and TM sensor image of the Landsat 5 satellite. Estimates were made for the scene on day $6 / 20^{\text {th }} / 2003$. Considering only the areas related to the eucalyptus crops at seven years of age, it was obtained mean values of net radiation $(R n)$, soil heat flux $(G)$, sensible heat flux $(H)$ and latent heat flux $(L E)$ of $420.12 \mathrm{~W} \mathrm{~m}^{-2}, 81.80 \mathrm{~W} \mathrm{~m}^{-2}$, $149.93 \mathrm{~W} \mathrm{~m}^{-2}, 188.39 \mathrm{~W} \mathrm{~m}^{-2}$, respectively. For actual hourly evapotranspiration $\left(\mathrm{ETr}_{h}\right)$, the mean value obtained was $0.28 \mathrm{~mm} \mathrm{~h}^{-1}$. The estimates are consistent with literature data, but future studies with greater experimental control should be carried out.
\end{abstract}

Keywords: Eucalyptus plantation, Energy fluxes and Remote sensing.

\footnotetext{
${ }^{1}$ Recebido em 17.10.2009 e aceito para publicação em 18.04.2011.

${ }^{2}$ Programa de Pós-Graduação em Ciencia Florestal pela Universidade Federal de Viçosa, MG. E-mail: < sadymenezes@yahoo.com.br>. ${ }^{3}$ Departamento de Engenharia Agrícola da Universidade Federal de Viçosa, MG. E-mail: <g.sediyama@ufv.br>.

${ }^{4}$ Departamento de Engenharia Florestal da Universidade Federal de Viçosa. E-mail: <vicente@ufv.br>e < gleriani@gmail.com>.

${ }_{5}^{5}$ Pesquisador da Embrapa Monitoramento por Satélite. E-mail: <ricardo@cnpm.embrapa.br>e < andradeguimaraes@gmail.com>.
} 


\section{INTRODUÇÃO}

Entre as inúmeras variáveis ambientais que podem influenciar o crescimento e o desenvolvimento vegetal, as variáveis climáticas têm sido fundamentais em vários estudos da silvicultura (LIMA;FREIRE, 1976; MIELKE et al., 1999; STAPE, 2002; MAFIA et al., 2006; TONELLO;TEIXEIRA FILHO, 2007; SANTANA et al., 2008; CARNEIRO et al., 2008; CUNHA et al., 2009). Segundo Souza et al. (2006), as principais variáveis que afetam o crescimento das árvores são: radiação solar, temperatura e disponibilidade hídrica. A radiação solar constitui a fonte primária de energia para o processo fotossintético (PIRES O’BRIEN, 1995). Santana et al. (2008) relatam que a produção de uma floresta é determinada pela quantidade de radiação solar interceptada no dossel e pela eficiência de conversão dessa radiação em biomassa. No entanto, processos fisiológicos e bioquímicos também podem ser influenciados tanto pela temperatura quanto pela demanda hídrica (CAMPOS, 1970; PEREIRA et al., 2002; SOUZA et al., 2006).

Jarvis (1985), citado por Santana et al. (2008), realizou uma avaliação crítica de vários trabalhos e demonstrou haver evidências sobre a correlação da produção em florestas de coníferas com a água disponível no solo. Já Hingston e Galbraith (1998) analisaram 31 sítios de eucalipto na Austrália e concluíram que a idade e a precipitação média anual explicavam 85\% do crescimento do diâmetro e $89 \%$ da altura média dos povoamentos. Para Maestri (2003), as variáveis climáticas que mais influenciaram a altura dominante de povoamentos de Eucalyptus grandis foram a precipitação, a temperatura (máxima e mínima) e a evapotranspiração.

A evapotranspiração (ET) é uma variável que pode ser medida por meio de equipamentos, como os lisímetros, ou estimada a partir do balanço hídrico no solo ou de dados meteorológicos aplicados a equações (PEREIRA et al., 1997), como a utilizada no Boletim da FAO 56 de Penman-Monteith (ALLEN et al., 1998). Assad e Sano (1998) relatam que os vários métodos de estimativa da ET podem ser agrupados em três categorias: método do balanço hídrico, métodos micrometeorológicos e métodos empíricos. Porém, esses métodos são limitados porque estimam valores pontuais da ET para um local específico e não para uma escala regional. Essa limitação motivou o uso de dados obtidos por sensoriamento remoto para a avaliação da ET em grandes áreas (COSTA,
1997). A principal vantagem do uso do sensoriamento remoto é que a ET pode ser calculada sem a necessidade de quantificar os complexos processos hidrológicos (ANDRADE et al., 2009). Nesse sentido, alguns algoritmos vêm sendo aplicados na estimativa dos componentes do balanço de energia e, por conseguinte, na obtenção da ET em escala regional, entre os quais o algoritmo SEBAL (Surface Energy Balance Algorithm for Land), que foi desenvolvido por Bastiaanssen em 1995 e se destaca por exigir poucas medições em campo (BEZERRA, 2004).

Segundo Bastiaanssen (2000), o SEBAL é um algoritmo para determinação dos mapas de evapotranspiração para grandes áreas. Ele é processado por meio de rotinas computacionais que predizem um balanço completo da radiação e da energia sobre a superfície da Terra. Utiliza imagens coletadas pelo sensor TM do satélite Landsat 5 ou por outro sensor que colete faixas do espectro na região do visível, infravermelho refletivo e termal.

Diante do exposto, este trabalho teve como objetivo estimar os componentes do balanço de energia e da evapotranspiração em plantios de eucaliptos com aplicação do algoritmo SEBAL e imagem do sensor TM do satélite Landsat 5, no Município de Santa Bárbara, MG.

\section{MATERIAL E MÉTODOS}

A área de estudo está localizada na região do Município de Santa Bárbara, MG (latitude 1957'34'S Gr e longitude 4324’55'’O Gr, Fuso 23) (Figura 1). Essa região tem altitudes que variam de $630 \mathrm{~m}$ a $880 \mathrm{~m}$.

Segundo a classificação de Köppen, o clima da região é do tipo Cwb (ANTUNES, 1986), ou seja, tropical de altitude com verões frescos e estação seca bem definida, com os meses de outubro a abril úmidos, e os de maio a setembro relativamente secos (NUNES; PEDRALLI, 1995). A temperatura média anual está entre $19^{\circ} \mathrm{C} \mathrm{e} 20^{\circ} \mathrm{C}$, com temperatura máxima de $32^{\circ} \mathrm{C}$ (janeiro) e mínima de $12,9^{\circ} \mathrm{C}$ (junho-julho). Os solos da região de estudo são classificados como Latossolo VermelhoAmarelo distrófico com textura argilosa, afloramentos de rochas mais Cambissolo Háplico Tb distrófico e Neossolo Litólico distrófico (ROCHA; CAMPOS, 1994). A vegetação dessa região, segundo os mapas e descrições dos domínios morfoclimáticos da América do Sul (AB’SABER, 1977), situa-se na transição entre os biomas Mata Atlântica e Cerrados. Atualmente, predominam

Revista Árvore, Viçosa-MG, v.35, n.3, Edição Especial, p.649-657, 2011

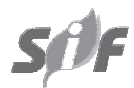




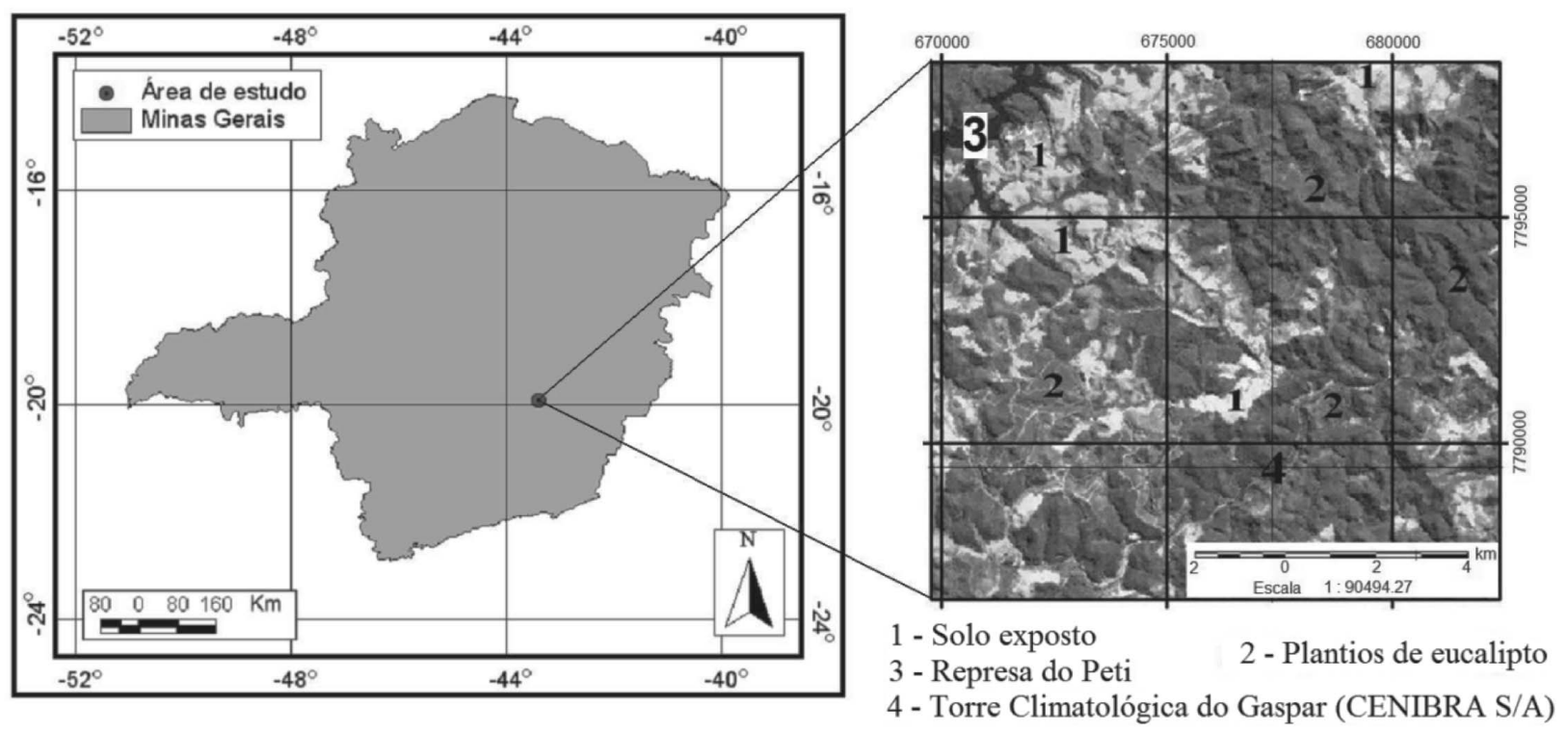

Figura 1 - Localização da região de estudo e imagem Landsat 5 - TM do dia 20/06/2003.

Figure 1 - Location of the study area and Landsat 5 - TM image obtained in June $20^{\text {th }}, 2003$.

na região plantações de eucalipto da CENIBRA (Celulose Nipo-Brasileira S.A.) e de produtores rurais sob o sistema de fomento florestal mediante parceria feita com indústrias siderúrgicas para o suprimento de carvão vegetal para seus altos fornos. Em média, o plantio de eucalipto estudado tinha sete anos de idade.

Para obtenção dos componentes do balanço de energia e da evapotranspiração por meio do algoritmo SEBAL (Figura 2), foram utilizados dados meteorológicos (temperatura do ar, radiação e velocidade do vento) da estação climatológica denominada Torre Climatológica do Gaspar (latitude de 1959’00' 'S Gr e longitude de 4318'19'’ O Gr. Fuso 23), de propriedade da empresa CENIBRA. Essa estação climatológica localiza-se a 847 m de altitude (Figura 1), no Distrito de Florália, pertencente ao Município de Santa Barbara, MG. Também foi utilizada uma cena do sensor TM (Thematic Mapper) do satélite Landsat 5 (órbita/ponto 217/74) contendo as sete bandas espectrais obtidas do catálogo de imagens do Instituto Nacional de Pesquisas Espaciais (INPE) por meio do sítio http://www.dgi.inpe.br/CDSR/. As imagens utilizadas têm resolução espacial de 30 m nas bandas 1, 2, 3, 4, 5 e 7 e de $120 \mathrm{~m}$ na banda 6 (termal). Para o estudo, utilizou-se uma cena do dia 20 de junho de 2003, que não apresentava problemas com cobertura de nuvens.
O algoritmo SEBAL utiliza a equação do balanço de energia à superfície para estimar o fluxo de calor latente (LE) como um resíduo dos demais componentes - fluxo de calor sensível (H), fluxo de calor no solo $(\mathrm{G})$ e saldo de radiação $(\mathrm{Rn})$.

$L E=\mathrm{Rn}-\mathrm{G}-\mathrm{H}$

em que LE, Rn, H e G são dados em W m ${ }^{-2}$. O Rn foi a primeira variável a ser obtida (Figura 2) da equação do balanço de energia. Allen et al. (2002) apresentam em detalhes todas as etapas envolvidas na obtenção do $\mathrm{R}$

Em seguida, G foi estimado por meio da aplicação da equação desenvolvida por Bastiaanssen (2000):

$\mathrm{G}=\left[\frac{\mathrm{T}_{\mathrm{s}}}{\alpha}\left(0,0038 \alpha+0.0074 \alpha^{2}\right)\left(1-0,98 \mathrm{NDVI}^{4}\right)\right] \mathrm{Rn}$

em que $\mathrm{G}$ é o fluxo de calor no solo $\left(\mathrm{W} \mathrm{m}^{-2}\right)$, Ts é a temperatura da superfície (K), a é o albedo da superfície, NDVI é o índice de vegetação da diferença normalizada (Normalized Difference Vegetation Index), e Rn é o saldo de radiação à superfície $\left(\mathrm{W} \mathrm{m}^{-2}\right)$. Obtido o valor de $\mathrm{G}$, iniciou-se uma nova série de passos para a obtenção do fluxo de calor sensível (H) (Figura 3). 


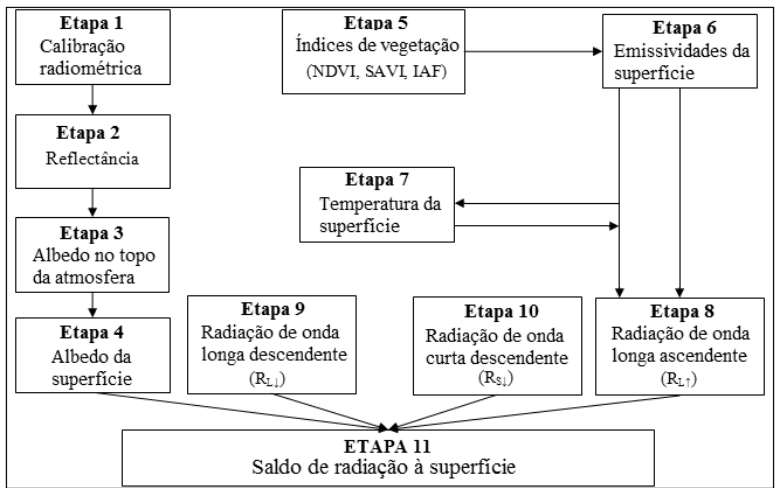

Figura 2 - Fluxograma das etapas do processamento do saldo de radiação à superfície. Fonte: adaptado de SILVA et al., 2005.

Figure 2 - Processing stages of surface net radiation flowchart.

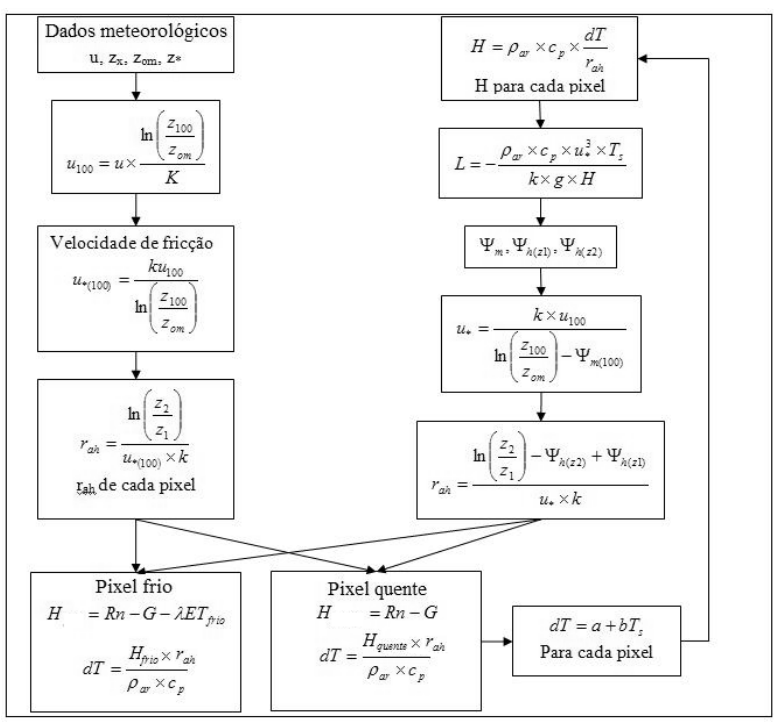

Figura 3 - Cálculo do fluxo de calor sensível. Fonte: Bezerra (2004).

Figure 3 - Estimate of sensitive heat flux.

Para a estimativa de $\mathrm{H}$, o processo teve início considerando a condição de atmosfera neutra. Primeiramente, foram aplicadas as expressões sugeridas por Allen et al. (2002) para obter o parâmetro de rugosidade inicial, a velocidade de fricção inicial, a velocidade do vento a uma altura (z) de $100 \mathrm{~m}$ (chamada de blending height, altura de mistura, em que os efeitos da rugosidade da superfície são desprezíveis) e a resistência aerodinâmica inicial. Nos passos seguintes, foi utilizado o parâmetro de rugosidade $\left(\mathrm{z}_{\mathrm{om}}\right.$ ) obtido em função do índice de vegetação ajustado para correção dos efeitos do solo (Soil Adjusted Vegetation Index - SAVI).

O SEBAL utiliza dois pixels denominados “pixels âncora” para fixar condições limite no balanço de energia. Esses pixels são chamados de quente e frio e ficam situados na área de estudo. O pixel quente foi localizado em uma área seca ou em área de campos vazios (áreas já colhidas ou em preparo agrícola) para a qual se assume que não existe evaporação e que H é máximo. Foram evitadas áreas impermeabilizadas (asfaltos), telhados e áreas extremamente quentes. O pixel frio selecionado foi o de uma superfície de lago (Represa do Peti) com a temperatura do ar $\left(\mathrm{T}_{\mathrm{a}}\right)$ próxima à da superfície e a temperatura da superfície $\left(\mathrm{T}_{\mathrm{s}}\right)$ consideradas iguais para esse pixel. Assim, assumiu-se que H é igual a zero e, então, determinou-se o fluxo de calor latente máximo. Por meio das informações dos “pixels âncora”, foi possível estabelecer uma relação linear de diferença da temperatura da superfície. A diferença de temperatura $\left(\mathrm{dT},{ }^{\circ} \mathrm{C}\right)$ foi calculada conforme Allen et al. (2002):

$\mathrm{dT}=\mathrm{a}+\mathrm{bT}_{\mathrm{s}}$

em que $a$ e $b$ são os coeficientes da equação linear e $\mathrm{T}_{\mathrm{s}}$ é a temperatura da superfície $\left({ }^{\circ} \mathrm{C}\right)$.

Com a obtenção de dT, foi possível obter a estimativa inicial de H pela equação:

$$
H=\rho_{a r} c_{p} \frac{d T}{r_{a h}}
$$

em que $\tilde{n}_{a r}$ é a densidade do ar úmido $\left(1,15 \mathrm{~kg} \mathrm{~m}^{-3}\right)$, $\mathrm{C}_{\mathrm{p}}$ é o calor específico do ar à pressão constante (1.004 $\left.\mathrm{J} \mathrm{kg}^{-1} \mathrm{~K}^{-1}\right), \mathrm{r}_{\text {ah }}$ é a resistência aerodinâmica $\left(\mathrm{s} \mathrm{m}^{-1}\right)$, e dT é a diferença de temperatura $\left({ }^{\circ} \mathrm{C}\right)$.

A próxima etapa consistiu em considerar a condição de estabilidade atmosférica, realizando correções nos valores de $\mathrm{H}$ em processo iterativo. Para isso, aplicou-se a teoria da similaridade de Monin-Obukhov (L, em m) para saber a condição de estabilidade da atmosfera, ou seja, se ela é instável ( $L<0)$, estável $(L>0)$ ou neutra $(\mathrm{L}=0)$ :

$L=-\frac{\rho_{a r} c_{p} u_{*}{ }^{3} T_{S}}{k g H}$

Revista Árvore, Viçosa-MG, v.35, n.3, Edição Especial, p.649-657, 2011 
em que $\mathrm{r}_{\mathrm{ar}}$ é a densidade do ar úmido $\left(1,15 \mathrm{kgm}^{-3}\right)$, $c_{p}$ é o calor específico do ar à pressão constante (1.004 J kg-1 $\left.\mathrm{K}^{-1}\right), \mathrm{u}_{*}$ é a velocidade de friç̧ão em cada pixel da imagem $\left(\mathrm{m} \mathrm{s}^{-1}\right), \mathrm{T}_{\mathrm{s}}$ é a temperatura da superfície (K), g é a constante gravitacional $\left(9,81 \mathrm{~m} \mathrm{~s}^{-2}\right)$, H é o fluxo de calor sensível $\left(\mathrm{W} \mathrm{m}^{-2}\right)$.

Posteriormente, obtiveram-se os valores das correções de estabilidade para o transporte de momentum $\left(\mathrm{y}_{\mathrm{m}}\right)$ e de calor sensível $\left(\mathrm{y}_{\mathrm{h}}\right)$ conforme formulações sugeridas por Allen et al. (2002). Assim, realizaram-se as correções necessárias no valor da velocidade de fricção ( $\left.u^{*}\right)$ e do $r_{\text {ah }}$. Em seguida, retornou-se ao cálculo da função da diferença de temperatura (dT), repetindo-se os cálculos mencionados anteriormente até que fosse observada estabilidade nos valores sucessivos de $\mathrm{dT}$ e $\mathrm{r}_{\mathrm{ah}}$ no pixel quente. Por fim, obteve-se o fluxo de calor latente (LE) como um resíduo do balanço de energia (equação 1) e estimou-se a evapotranspiração real horária $\left(\operatorname{ETr}_{h}\right.$, em $\mathrm{mm} \mathrm{h}^{-1}$ ) pela seguinte equação:

$\operatorname{ETr}_{h}=\frac{L E \times 0,0036}{2,45}$

\section{RESULTADOS E DISCUSSÃO}

A Figura 4a a 4f apresentam, respectivamente, o índice de área foliar (IAF), o saldo de radiação (Rn), o fluxo de calor no solo (G), o fluxo de calor sensível $(\mathrm{H})$, o fluxo de calor latente (LE) e a evapotranspiração real horária $\left(\mathrm{ETr}_{\mathrm{h}}\right)$ para o plantio de eucalipto na região do Município de Santa Bárbara, MG. Conforme Figura 4a, o IAF variou de $0,0 \mathrm{~m}^{2} \mathrm{~m}^{-2}$ (áreas de solo exposto e de corpos d’água) a 3,00 $\mathrm{m}^{2} \mathrm{~m}^{-2}$ (áreas com plantio de eucalipto), com média de $1,90 \mathrm{~m}^{2} \mathrm{~m}^{-2}$. Para plantações de eucalipto com diferentes idades, na regional de produção de Aracruz, ES, Xavier et al. (2002) obtiveram IAF variando de $1,7 \mathrm{~m}^{2} \mathrm{~m}^{-2}$ (plantios de 5 anos) a $4,3 \mathrm{~m}^{2} \mathrm{~m}^{-2}$ (plantios de 2 anos), com média de $2,86 \mathrm{~m}^{2} \mathrm{~m}^{-2}$. Almeida e Soares (2003) verificaram IAF máximo $\left(3,5 \mathrm{~m}^{2} \mathrm{~m}^{-2}\right)$ em plantações de eucalipto entre 3 e 4 anos de idade.

Na Figura 4b, nota-se que Rn variou de 381 W m ${ }^{-2}$ a 532 W m² . Já nas Figuras 4c e 4d, observamse que $\mathrm{G}$ e $\mathrm{H}$ oscilaram de $34 \mathrm{~W} \mathrm{~m}^{-2}$ (eucalipto adensado) a $140 \mathrm{~W} \mathrm{~m}^{-2}$ (corpos d'água) e de $120 \mathrm{~W} \mathrm{~m}^{-2}$ (eucalipto adensado) a $160 \mathrm{~W} \mathrm{~m}^{-2}$ (solo exposto), respectivamente.
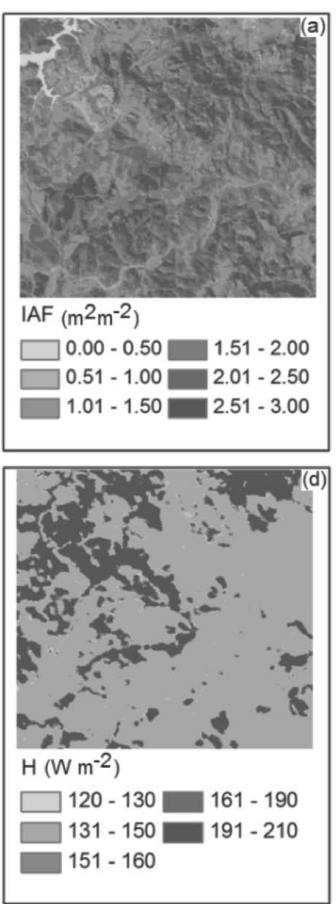
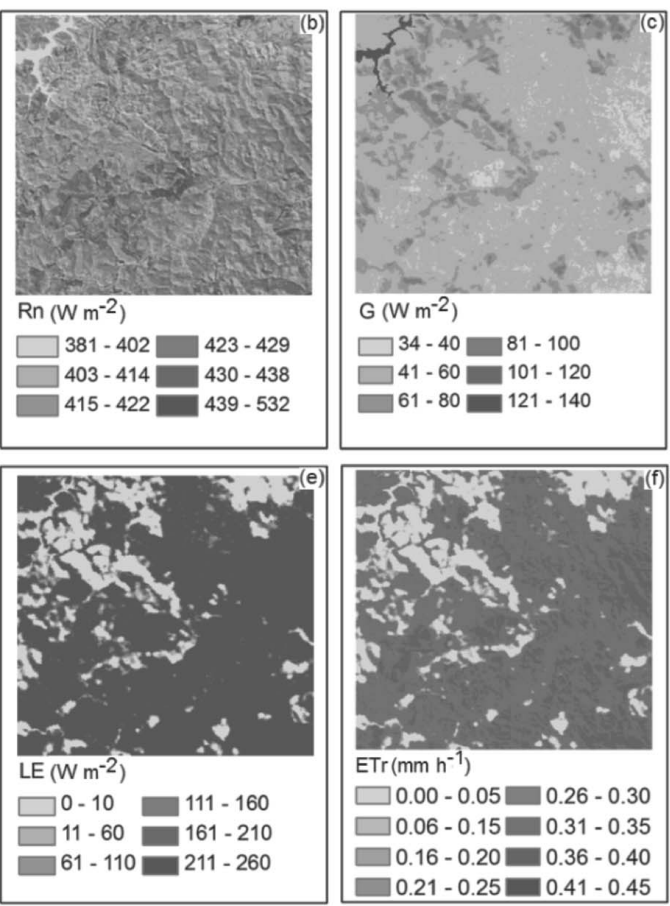

Figura 4 - (a) índice de área foliar (IAF, $\left.\mathrm{m}^{2} \mathrm{~m}^{-2}\right)$, (b) saldo de radiação (Rn, $\mathrm{W} \mathrm{m}^{-2}$ ), (c) fluxo de calor no solo (G, W m $\left.{ }^{-2}\right),(\mathrm{d})$ fluxo de calor sensível $\left(\mathrm{H}, \mathrm{W} \mathrm{m}^{-2}\right)$, (e) fluxo de calor latente $\left(\mathrm{LE}, \mathrm{W} \mathrm{\textrm {m } ^ { - 2 }}\right.$ ) e (f) evapotranspiração real horária $\left(\mathrm{ETr}, \mathrm{mm} \mathrm{h}^{-1}\right.$ ) para o plantio de eucalipto.

Figure 4 - (a) leaf area index, (b) net radiation, (c) soil heat flux, (d) sensible heat flux, (e) latent heat flux, ( $f$ ) actual hourly evapotranspiration for the Eucalyptus crop. 
Na Figura 4e e 4f, observam-se que LE e ETr apresentam valores máximos nas áreas de eucalipto e mínimos nas áreas com exposição do solo.

A Tabela 1 mostra os valores médios dos componentes do balanço de energia. O valor médio de Rn encontrado para o eucalipto foi de 420,12 $\mathrm{W} \mathrm{m}^{-2}$ (Tabela 1), que está próximo ao observado por Gomes (2009) em área com vegetação nativa (cerrado) e eucalipto (300 $\mathrm{W} \mathrm{m}^{-2}$ a $400 \mathrm{~W} \mathrm{~m}^{-2}$ ) em estudo realizado na região do Município de Santa Rita do Passa Quatro, SP, com aplicação do algoritmo SEBAL e imagem Landsat 5-TM do dia 14 de junho de 2005. Além disso, os dados médios de $\mathrm{G}\left(81,80 \mathrm{~W} \mathrm{~m}^{-2}\right)$, H $\left(149,39 \mathrm{~W} \mathrm{~m}^{-2}\right)$ e LE $\left(188,39 \mathrm{~W} \mathrm{~m}^{-2}\right)$, apresentados na Tabela 1 , também estão próximos aos valores observados por Gomes (2009) para área de vegetação nativa (cerrado) e eucalipto.

Para o plantio de eucalipto (aproximadamente sete anos de idade), a evapotranspiração real horária $\left(\mathrm{ETr}_{\mathrm{h}}\right)$

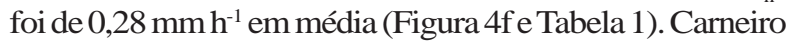
et al. (2008), ao utilizarem o método de Penman-Monteith em plantios de eucalipto, encontraram valores da ordem de $0,19 \mathrm{~mm} \mathrm{~h}^{-1}$ (irrigado) e de $0,17 \mathrm{~mm} \mathrm{~h}^{-1}$ (não irrigado). Em estudo realizado com plantios de Eucalyptus grandis, com nove anos de idade, na região de Aracruz, ES, Mielke et al. (1999) obtiveram valores médios de demanda de água da ordem de $0,54 \mathrm{~mm} \mathrm{~h}^{-1}, 0,50 \mathrm{~mm} \mathrm{~h}^{-1}, 0,40 \mathrm{~mm} \mathrm{~h}^{-1}$, $0,21 \mathrm{~mm} \mathrm{~h}^{-1}$ e $0,18 \mathrm{~mm} \mathrm{~h}^{-1}$ para os meses de janeiro, março, abril, junho e agosto, respectivamente. No entanto, Gomes (2009) obteve $0,31 \mathrm{~mm} \mathrm{~h}^{-1}$ para vegetação de cerrado e eucalipto ao utilizar o algoritmo SEBAL e imagem Landsat 5 - TM do dia 14 de junho de 2005.

Em princípio, não é aconselhável extrapolar o valor médio de evapotranspiração real horária $\left(0,28 \mathrm{~mm} \mathrm{~h}^{-1}\right)$ para uma escala diária $\left(6,72 \mathrm{~mm} \mathrm{~d}^{-1}\right)$, principalmente

Tabela 1 - Valores médios dos componentes do balanço de energia na superfície da Terra $\left(\mathrm{W} \mathrm{m}^{-2}\right)$ para o plantio de eucalipto.

Table 1 - Mean values of energy balance components on the Earth's surface $\left(\mathrm{W} \mathrm{m}^{-2}\right)$ for the Eucalyptus crop.

\begin{tabular}{lc}
\hline $\begin{array}{c}\text { Componentes do balanço } \\
\text { de energia }\end{array}$ & Valores médios $\left(\mathrm{W} \mathrm{m}^{-2}\right)$ \\
\hline Saldo de radiação $(\mathrm{Rn})$ & 420,12 \\
Fluxo de calor no solo $(\mathrm{G})$ & 81,80 \\
Fluxo de calor sensível $(\mathrm{H})$ & 149,93 \\
Fluxo de calor latente (LE) & 188,39 \\
\hline
\end{tabular}

por considerar-se um valor médio horário calculado com imagem de satélite (instantâneo) e dados meteorológicos para o momento da passagem do satélite sobre a área de estudo. Nesse caso, ao efetuar-se a extrapolação, supõe-se a taxa evapotranspirométrica como constante ao longo do dia. Essa suposição poderá acarretar erros consideráveis que carecem ser analisados em pesquisas futuras por meio de análises de validação com maior controle dos dados experimentais. Contudo, ao fazer uma simples comparação com dados encontrados na literatura, verifica-se que o valor extrapolado encontra-se respaldado por estar dentro da faixa de variação observada em plantios de eucalipto. Por exemplo, Dye (1987) encontrou oscilação entre $2,40 \mathrm{~mm} \mathrm{~d}^{-1} \mathrm{e}$ $8,60 \mathrm{~mm} \mathrm{~d}^{-1} \mathrm{em}$ Eucalyptus grandis com $22 \mathrm{~m}$ de altura. Facco (2004) observou valores médios oscilando entre 2,90 $\mathrm{mm} \mathrm{d}^{-1}$ e 3,40 $\mathrm{mm} \mathrm{d}^{-1}$ (plantios de dois a quatro anos de idade). Já Sacramento Neto (2001) encontrou valores variando de 8,60 a $10,00 \mathrm{~mm} \mathrm{~d}^{-1}$ em eucalipto com dois anos de idade. Para plantios de Eucalyptus grandis com três anos de idade, no Município de Santa Bárbara, MG, Leite et al. (1999) encontraram valores médios de evapotranspiração diária no período de menor e maior disponibilidade hídrica de $0,96 \mathrm{~mm} \mathrm{~d}^{-1}$ e 4,61 $\mathrm{mm} \mathrm{d}^{-1}$, respectivamente. Soares et al. (2001), ao utilizarem dados de campo e imagem Landsat 5 - TM na obtenção do balanço de água em plantios de eucalipto, observaram demanda de água pelas plantas oscilando entre $1,10 \mathrm{~mm} \mathrm{~d}^{-1}$ e $5,80 \mathrm{~mm} \mathrm{~d}^{-1} \mathrm{de}$ acordo com a época do ano. Tatsch (2006) monitorou os fluxos de energia em plantio de eucalipto na microrregião de Ribeirão Preto, SP, por meio de torre micrometeorológica no período de 22/07/2005 a 06/02/2006. Os resultados encontrados pelo autor mostram que a evapotranspiração diária teve variação entre $1,00 \mathrm{~mm} \mathrm{~d}^{-1}$ e $8,00 \mathrm{~mm} \mathrm{~d}^{-1}$, com médias para os períodos seco e úmido de $1,70 \mathrm{~mm} \mathrm{~d}^{-1}$ e $5,20 \mathrm{~mm} \mathrm{~d}^{-1}$, respectivamente.

\section{CONCLUSÕES}

Os valores médios das estimativas dos componentes do balanço de energia e da evapotranspiração em plantios de eucaliptos com aplicação do algoritmo SEBAL e imagem Landsat 5 - TM mostraram-se coerentes com a literatura. No entanto, para pesquisas futuras, sugere-se a calibração do algoritmo SEBAL nas diversas fases de desenvolvimento e/ou crescimento do eucalipto,

Revista Árvore, Viçosa-MG, v.35, n.3, Edição Especial, p.649-657, 2011 
com análise espaço-temporal de variáveis ambientais referentes ao solo (umidade, temperatura, minerais etc.), biomassa vegetal, área foliar, dossel, radiação incidente, relevo, inclinação e posição e/ou sentido em que a encosta está em relação à trajetória do sol. Essas informações poderão ser fundamentais para respaldar cientificamente a elaboração de uma metodologia que possibilite, em plantios de eucaliptos, a extrapolação da evapotranspiração horária para uma escala diária.

\section{REFERÊNCIAS}

AB'SABER, A. N. Os domínios morfoclimáticos da América do Sul. Geomorfologia, v.53, p.1-23, 1977.

\section{ALLEN, R. G. et al. Surface Energy}

Balance Algorithm for Land (SEBAL). Advanced training and Users Manual. Kimberly, Idaho: 2002. 98p.

\section{ALLEN, R. G. et al. Crop}

evapotranspiration: guidelines for computing crop water requirements. 1998. 300p. (FAO Irrigation and Drainage Paper, 56). Disponível em: <http://www.kimberly.uidaho.edu/ water/fao56/index.html>. Acesso em: 08 jun. 2010.

ALMEIDA, A. C.; SOARES, J. V. Comparação entre uso de água em plantações de Eucalyptus grandis e floresta ombrófila densa (Mata Atlântica) na costa leste do Brasil. Revista Árvore, v.27, n.2, p.159-170, 2003.

ANDRADE, R. G. et al. Mapeamento de parâmetros biofísicos e da evapotranspiração no Pantanal usando técnicas de sensoriamento remoto. In: SIMPÓSIO DE GEOTECNOLOGIAS NO PANTANAL, 2., 2009, Corumbá. Anais...

Corumbá: Embrapa Informática Agropecuária/INPE, 2009. p.695-704. Disponível em: <http:// www.geopantanal2009.cnptia.embrapa.br/cd/pdf/ p105.pdf>. Acesso em: 02 jun. 2010.

ANTUNES, F. N. Caracterização climática do Estado de Minas Gerais. Informe Agropecuário, v.12, n.138, p.9-13, 1986.

ASSAD, E. D.; SANO, E. E. Sistemas de informações geográficas: aplicações na agricultura. 2.ed. Brasília: Embrapa-SPI/EmbrapaCPAC, 1998. 434p.
BASTIAANSSEN, W. G. M. SEBAL - Based Sensible and Latent Heat Fluxes in the Irrigated Gediz Basin. Turkey. Journal of Hydrology, v.229, n.1, p.87-100, 2000.

BEZERRA, M. V. C. Balanço de energia em áreas irrigadas utilizando técnicas de sensoriamento remoto. 2004. 108f. Dissertação (Mestrado em Meteorologia) Universidade Federal de Campina Grande, Campina Grande, 2004.

CAMPOS, J. C. C. Principais fatores do meio que afetam o crescimento das árvores. Floresta, n.3, p.45-52, 1970.

CARNEIRO, R. L. C. et al. Consumo de água em plantios de eucalipto: Parte 2 Modelagem da resistência estomática e estimativa da transpiração em tratamentos irrigados e nãoirrigados. Revista Árvore, v.32, n.1, p.11-18, 2008.

COSTA, M. C. Estimativa da evapotranspiração regional por meio de imagens orbitais. 1997. $52 \mathrm{f}$. Dissertação (Mestrado em Meteorologia Agrícola) - Universidade Federal de Viçosa, Viçosa, MG, 1997.

CUNHA, A. C. M. C. M. et al. Relações entre variáveis climáticas com produção e enraizamento de miniestacas de eucalipto. Revista Árvore, v.33, n.2, p.195-203, 2009.

DYE, P. J. Estimating water use by Eucalyptus grandis with the Penman-Monteith equation. In: VANCOUVER SYMPOSIUM - FOREST

HIDROLOGY AND WATERSHED

MANAGEMENT, 1987, Vancouver.

Proceedings... Vancouver: International Association of Hidrological Sciences, 1987. p.329-337.

FACCO, A. G. Modelagem e simulação geoespacial dos componentes do balanço hídrico para plantios de eucaliptos em áreas de relevo ondulado. 2004. 87f. Dissertação (Mestrado em Meteorologia Agrícola) - Universidade Federal de Viçosa, Viçosa, MG, 2004. 
GOMES, H. B. Balanço de radiação e energia em áreas de cultivo de canade-açúcar e Cerrado no Estado de São Paulo mediante imagens orbitais. 2009. 108f. Tese (Doutorado em Meteorologia) Universidade Federal de Campina Grande, Campina Grande, 2009.

LEITE, F. P. et al. Relações hídricas em povoamento de eucalipto com diferentes densidades populacionais. Revista Brasileira de Ciência do Solo, v.23, p.9-16, 1999. Disponível em: <http://sbcs.solos.ufv.br/solos/ revistas/v23n1a02.pdf>. Acesso em: 22 jun. 2010.

LIMA, W. P.; FREIRE, O. Evapotranspiração em plantações de eucalipto e de pinheiro, e em vegetação herbácea natural. IPEF, n.12, p.103117, 1976. Disponível em: <http://www.ipef.br/ publicacoes/scientia/nr12.asp $>$. Acesso em: 08 jun. 2010.

HINGSTON, F. J.; GALBRAITH, J. H. Application of the process-based model BIOMASS to Eucalyptus globulus ssp. globulus plantations on ex-farmland in south western Australia: II. Stemwood production and seasonal growth. Forest Ecology and Management, v.106, p.157-168, 1998.

MAESTRI, R. Modelo de crescimento e produção para povoamentos clonais de Eucalyptus grandis considerando variáveis ambientais. 2003. 143f. Tese (Doutorado em Engenharia Florestal) - Universidade Federal do Paraná, Curitiba, 2003.

MAFIA, R. G. et al. Variáveis climáticas associadas à incidência de mofo-cinzento em eucalipto. Fitopatologia Brasileira, v.31, n.2, p.152-157, 2006.

MIELKE, M. S. et al. Stomatal control of transpiration in the canopy of a clonal Eucalyptus grandis plantation. Trees, v.13, n.3, p.152-160, 1999.

NUNES, Y. R. F.; PEDRALLI, G. Desenvolvimento de metodologia para adensamento e recomposição da vegetação na EPDA-Peti,. MG. BIOS Cadernos do Departamento de Ciências Biológicas da PUC-MG, v.2, n.3, p.53-61, 1995.
PEREIRA, A. R.; VILLA NOVA, N.; SEDIYAMA, G. Evapo(transpi)ração. Piracicaba: FEALQ, 1997. 183p.

PEREIRA, A. R.; ANGELOCCI, L. R.; SENTELHAS, P. C. Agrometeorologia: fundamentos e aplicações práticas. Guaíba: Agropecuária, 2002. 478p.

PIRES O’BRIEN, M. J. Ecologia e modelamento de florestas tropicais. Belém: FCAP, 1995. 400p.

ROCHA, M. G. B.; CAMPOS, W. O. Clonagem intensiva em Eucalyptus grandis na CENIBRA. In: REUNIÃO REGIONAL SOBRE CLONAGEM INTENSIVA EM EUCALYPTUS, 1., 1994, Aracruz. Anais... Aracruz: IPEF, 1994. p.28-43. Disponível em: <http://www.ipef.br/publicacoes/ reuniao_clonagem_intensiva/>. Acesso em: 08 jun. 2010.

SACRAMENTO NETO, O. B. Balanço hídrico em plantios jovens de eucalipto na região de Belo Oriente MG. 2001. 77f. Dissertação (Mestrado em Meteorologia Agrícola) - Universidade Federal de Viçosa, Viçosa, MG, 2001.

SANTANA, R. C. et al. Estimativa da biomassa em plantios de eucalipto no Brasil. Revista Árvore, v.32, n.4, p.697-706, 2008.

SILVA, B. B.; LOPES, G. M.; AZEVEDO, P. V. Balanço de radiação em áreas irrigadas utilizando imagens Landsat 5 - TM. Revista Brasileira de Meteorologia, v.20, n.2, p.243-252, 2005.

SOARES, J. V.; XAVIER, A. C.; ALMEIDA, A. C. Balanço de água em eucaliptos com a caracterização do dossel por técnicas de Sensoriamento Remoto. In: SIMPÓSIO BRASILEIRO DE SENSORIAMENTO REMOTO, 10., 2001, Foz do Iguaçu. Anais... Foz do Iguaçu: INPE, 2001. p.139-147. Disponível em: < $\underline{\text { http:// }}$ marte.dpi.inpe.br/col/dpi.inpe.br/lise/2001/ 12.28.15.53/doc/@sumario.htm>.Acesso em:02 jun. 2010.

SOUZA, M. J. H. et al. Disponibilidade hídrica do solo e produtividade do eucalipto em três regiões da Bacia do Rio Doce. Revista Árvore, v.30, n.3, p.399-410, 2006. 
STAPE, J. L. Production ecology of clonal Eucalyptus plantation in northeastern Brazil. Fort Collins: USA, 2002. 225f. (Doctor of Philosophy, Department of Forest Sciences, Colorado State University/USA), Disponível em: $<$ http://www.ipef.br/servicos/teses/arquivos/ stape,jl.pdf $>$. Acesso em: 30 set. 2009.

TATSCH, J. D. Uma análise dos fluxos de superfície e do microclima sobre cerrado, cana-de-açúcar e eucalipto, com implicações para mudanças climáticas regionais. 2006. 112f. Dissertação (Mestrado em Ciências) - Universidade de São Paulo, São Paulo, 2006.
TONELLO, K. C.; TEIXEIRA FILHO, J. Respostas fisiológicas de dois clones de eucalipto submetidos a diferentes potenciais hídricos. In: SEMINÁRIO DE RECURSOS HÍDRICOS DA BACIA HIDROGRÁFICA DO PARAÍBA DO SUL: O EUCALIPTO E O CICLO HIDROLÓGICO, 1., 2007, Taubaté. Anais... Taubaté: UNITAU, 2007. p.287-294. Disponível em: <https://

www.agro.unitau.br:8443/dspace/bitstream/2315/ 112/1/287-294.pdf $>$. Acesso em: 02 jun. 2010.

XAVIER, A. C.; SOARES, J. V.; ALMEIDA, A. C. Variação do índice de área foliar em clones de eucalipto ao longo de seu ciclo de crescimento. Revista Árvore, v.26, n.4, p.421-427, 2002. 
